\title{
О развитии рыбного хозяйства Донецкой Народной Республики путем организации рыбоводства речных рыб
}

\author{
Валентина Малыгина, Ксения Антошина ", Татьяна Гончарова \\ Донецкий национальный университет экономики и торговли \\ имени Михаила Туган-Барановского, г. Донецк, Донецкая Народная Республика
}

Информация о статье

Поступила в редакичю:

31.08.2020

Принята

к опубликованию:

15.10 .2020

УДК 639.3(477.62)

JEL Q22

Ключевые слова:

развитие, рыбное хозяйство, Донецкая Народная Республика, технологии выращивания, способы выращивания

\section{Keywords:}

development, fisheries, Donetsk People's Republic, cultivation technologies, cultivation methods

\begin{abstract}
Аннотация
В статье раскрыта необходимость развития рыбного хозяйства Донеикой Народной Республики (далее - ДНР) путем организации рыбоводства речных рыб, пояснены причины трансформации потребительского рынка пищевых продуктов в сегменте рыбы и рыбных товаров, приведена характеристика технологий и способов разведения рыбы, проведены расчеты стоимости одного килограмма рыбы, выращенной экстенсивным и полуэкстенсивнымм способами.
\end{abstract}

On the Development of the Donetsk People's Republic Fisheries by Organizing River Fish Farming

Valentina Malygina, Ksenia Antoshina, Tatiana Goncharova

\section{Abstract}

The paper discloses the necessity to develop the fisheries in the Donetsk People's Republic by organizing river fish farming, explains the reasons for the consumer food market transformation in the segment of fish and fish products, describes the technologies and methods of the fish farming, calculates the cost of one kilogram of fish raised by extensive and semiextensive methods. Fisheries, as a type of entrepreneurial activity, will not bring instant profit, and even under the best conditions it can be in two to five seasons (it all depends on the growth rate and value of the breed). To have the income every season, with extensive fish farming, fry will have to be launched into the pond every year until the first year's youngsters become sexually mature and begin to reproduce themselves. To develop the fisheries, a proposal was made to create a laboratory for analyzing and confirming the quality of fish products in the Novoazovsky district, quotas for fishing, issues of amending the existing regulations and developing the new ones in the fisheries, as well as certain aspects of the fishermen interaction with the regulatory authorities and state enterprises.

* Aвтор для связи: kseniya.antoshuna@gmail.com

DOI: https://dx.doi.org/10.24866/2311-2271/2020-3/87-97 


\section{Введение}

Рыбные товары являются одним из жизненно важных пищевых продуктов для организма человека, так как в своем составе содержат легкоусвояемые жиры, витамины, макро- и микроэлементы. Кроме этого, рыбная продукция, как и любое мясо, содержит большое количество белка.

В последние 6 лет влияние внешних факторов на продовольственное обеспечение ДНР возросло, что является следствием продолжающейся глобализации экономики и ростом значимости продовольствия как одного из основных факторов политической и социально-экономической стабильности любого государства.

Трансформация ассортимента потребительского рынка пищевых продуктов существенно нивелировала сегмент рыбы и рыбной продукции. Причинами послужила территориальная корректировка границ Республики. Современная номенклатура рыбы и рыбных товаров представлена преимущественно консервированной продукцией (замороженная рыба, консервы, снеки).

Рацион питания взрослых потребителей должен содержать не менее 150-250 г рыбы в день. Для детей норма потребления меняется в зависимости от возраста [1]. При утвержденной потребительской корзине в ДНР данный показатель составляет 13 кг (рыбы и рыбных товаров) на одного человека в год [2]. Даже при заниженном уровне минимального количества потребления рыбы и рыбных товаров, зафиксированном в потребительской корзине, население фактически не употребляет столько рыбы.

Рыба и другие объекты промысла - млекопитающие, беспозвоночные и водоросли - занимают значительную часть рациона питания населения Республики. Наряду с полноценными белками в них содержатся легкоусвояемые жиры, витамины, макро- и микроэлементы.

Следовательно, в ДНР остро стоит вопрос возрождения и развития рыбного хозяйства, что свидетельствует об актуальности выбранной темы.

Целью исследования является обоснование развития рыбного хозяйства в ДНР путем организации рыбоводства речных рыб и разработки правительственных мероприятий, внедрение которых в практику позволит добиться насыщения внутреннего рынка, удовлетворения потребностей населения в рыбе и рыбных товарах, снижения розничных цен на рыбную продукцию и создания дополнительных рабочих мест.

\section{Материалы и методы исследования}

Для реализации поставленной цели решены следующие задачи:

- изучить сущность и предпосылки развития рыбного хозяйства как такового;

- проанализировать технологии и способы разведения рыбы;

- выявить особенности в ведении предпринимательства в рыбной отрасли;

- провести расчеты стоимости одного килограмма рыбы, выращенной экстенсивным и полуэкстенсивным способами;

- определить предложение для развития рыбного хозяйства в ДНР.

Объектом исследования является рыбное хозяйство Донецкой Народной Республики. Предметом - деятельность и мероприятия, которые будут способствовать развитию рыбного хозяйства в ДНР. 
В ходе работы применен аналитический и расчетный методы. Проведен расчет затрат на зарыбление водоема и себестоимость рыбы, полученной разными способами разведения (экстенсивный и полуэкстенсивный).

\section{Результаты исследования и их обсуждение}

В процессе становления ДНР как государственной единицы возникает много проблем, в том числе и в рыбном хозяйстве.

Еще сравнительно недавно Азовское море считалось самым рыбным в мире. Здесь добывались десятки различных видов рыб - от осетровых пород до бычков.

Этому способствовали уникальные природные условия: Азовское море не только самое «плодородное», но и самое мелкое. Солнечные лучи на всей его площади прогревают водную толщу до дна, что способствует развитию богатейшей кормовой базы.

Во времена СССР здесь работали десятки рыболовецких артелей, а рыбзаводы способствовали сохранению численности наиболее ценных пород, в первую очередь, осетровых. До недавнего времени на металлургическом комбинате имени Ильича существовала группа дочерних предприятий «Ильич-рыбак», одно из которых специализировалось на разведении осетровых.

В период с 90-х гг. прошлого столетия рыбным богатствам Азовского моря был нанесен колоссальный ущерб. В погоне за быстрой прибылью украинские бизнесмены при попустительстве чиновников не только хищнически вылавливали взрослую рыбу и рыбную молодь, но и уничтожали тралами придонный кормовой слой.

На сегодняшний день ДНР стремится быть независимой в сфере продовольственной обеспеченности, в том числе и в рыбном хозяйстве, поэтому проблемам восстановления рыбных богатств уделяется серьезное внимание. Руководству Министерства агропромышленной политики и продовольствия и специалистам агропромышленного комплекса Республики поставлена задача четкого квотирования вылова рыбы для всех предприятий и предпринимателей; создание в г. Новоазовск лаборатории по определению качества рыбной продукции.

Анализируя сложившуюся ситуацию, республиканские власти приняли решение создать государственное предприятие рыбного сектора, в перспективе способное обеспечить рацион каждого потребителя биологически ценными рыбными продуктами.

В настоящее время в Донецкой Народной Республике числится немногим более 700 прудов и водохранилищ общим объемом примерно 431245,1 тыс. м² и площадью зеркала 11 110,25 га [3,4]. Более подробно водные ресурсы освещены в табл. 1, согласно данным которой можно сказать, что ДНР в целом богата водными ресурсами.

Учитывая опыт Российской Федерации в развитии рыбной отрасли [5-7], правительство ДНР обеспечивает ежегодную разработку балансов ресурсов и использование основных видов сельскохозяйственной и рыбной продукции, сырья и продовольствия [8]. 
Таблицуа 1

Водные ресурсы Донецкой Народной Республики

\begin{tabular}{|c|c|c|c|c|c|c|c|c|c|}
\hline \multirow{2}{*}{$\begin{array}{c}\text { Наименование насе- } \\
\text { ленного пункта }\end{array}$} & \multicolumn{3}{|c|}{ Количество водоемов } & \multicolumn{3}{|c|}{ Объем, тыс. м $^{3}$} & \multicolumn{3}{|c|}{$\begin{array}{c}\text { Площадь зеркала } \\
\text { при НПУ, га }\end{array}$} \\
\hline & всего & $\begin{array}{c}\text { водохра- } \\
\text { нилищ }\end{array}$ & прудов & всего & $\begin{array}{c}\text { водохра- } \\
\text { нилищ }\end{array}$ & прудов & всего & $\begin{array}{l}\text { водохра- } \\
\text { нилищ }\end{array}$ & прудов \\
\hline Александровский район & 59 & 5 & 54 & 15060 & 7532 & 7529 & 623,53 & 239,2 & 364 \\
\hline Амвросиевский район & 86 & 11 & 75 & 28198,7 & 17571 & 10627,7 & 882,53 & 444,2 & 438,3 \\
\hline Новоазовский район & 37 & 2 & 35 & 73169,5 & 65640 & 7529,5 & 1150,32 & 900 & 250 \\
\hline Старобешевский район & 58 & 6 & 52 & 78115 & 68880 & 9235 & 1791,55 & 1436 & 392 \\
\hline Тельмановский район & 85 & 6 & 79 & 24192,4 & 15044 & 9148,4 & 790,6 & 364 & 426 \\
\hline Шахтерский район & 92 & 4 & 88 & 51731,4 & 37368 & 14363,4 & 1031,63 & 585 & 446 \\
\hline Ясиноватский район & 83 & 8 & 75 & 47408,2 & 34105 & 13303,2 & 1595,02 & 998.2 & 596 \\
\hline г. Горловка & 30 & 1 & 29 & 7952,8 & 9760 & 2192,8 & 212,74 & 106 & 106,74 \\
\hline г. Дебальцево & 4 & 1 & 3 & 20679 & 20500 & 179 & 482,2 & 476 & 6,2 \\
\hline г. Докучаевск & 8 & 1 & 7 & 2336,0 & 1260 & 1076 & 126,4 & 45 & 81,4 \\
\hline г. Донецк & 77 & 6 & 71 & 22721,6 & 13628 & 9093,6 & 662,71 & 351,5 & 311,21 \\
\hline г. Енакиево & 20 & 2 & 18 & 18681 & 14903 & 3778,3 & 459,19 & 353 & 106,19 \\
\hline г. Макеевка & 48 & 5 & 43 & 32982,7 & 28711 & 4271,7 & 913,3 & 717,6 & 195 \\
\hline г. Снежное & 2 & - & 2 & 647,8 & - & 647,8 & 19,41 & - & 19,41 \\
\hline г. Торез & 3 & - & 3 & 220 & - & 220,0 & 8,67 & - & 8,67 \\
\hline г. Харцызск & 4 & 2 & 2 & 5970 & 5740 & 230,0 & 282,6 & 275,5 & 7,1 \\
\hline г. Шахтерск & 13 & - & 13 & 1109 & - & 1009 & 74,35 & - & 74,35 \\
\hline г. Ясиноватая & 2 & - & 2 & 70 & - & 70,0 & 3,5 & - & 3,5 \\
\hline
\end{tabular}

Источник: составлено авторами

В целях повышения доступности пищевых продуктов для всех групп населения предполагаются следующие решения:

- формирование механизмов оказания адресной помощи группам населения, уровень доходов которых не позволяет им обеспечить полноценное питание;

- разработка унифицированных требований, предъявляемых на пищевых предприятиях к системам контроля и гармонизированных с рекомендациями международных.

В сфере производства и оборота сельскохозяйственной, рыбной продукции и продовольствия предстоит осуществить меры, направленные на:

- оптимизацию межотраслевых экономических отношений, которые стимулировали бы рост темпов расширенного воспроизводства, привлечение инвестиций;

- внедрение инноваций в сельском и рыбном хозяйстве;

- стабилизацию ценовой ситуации и формирование механизмов ценообразования на основе индикативных цен на основные виды продукции;

- стимулирование развития интеграции и кооперации в сфере производства, переработки и реализации сельскохозяйственной и рыбной продукции, сырья и продовольствия;

- ускоренное развитие инфраструктуры внутреннего рынка;

- разработку и реализацию программ технологической модернизации, освоение новых технологий, обеспечивающих повышение производительности труда и ресурсосбережения в сельском и рыбном хозяйстве, пищевой промышленности;

- формирование общего продовольственного рынка и единой товаропроводящей сети в рамках таможенного союза государств-членов Евразийского экономического сообщества. 
В рыбном хозяйстве, как и в другом любом животноводческом хозяйстве, применяется ряд технологий и способов, которые будут рассмотрены ниже.

Рыба растет в течение всей жизни, однако этот процесс неравномерен. Если молодые особи растут быстро, то с возрастом относительный прирост массы тела заметно снижается. Летом в период активного питания отмечается интенсивный рост, тогда как зимой этот процесс замедляется, а у некоторых видов, например у карпа, вообще прекращается из-за того, что при низких температурах он перестает питаться.

На рост рыбы влияет качество воды, а также наличие пищи. Замедляется рост и после полового созревания, поэтому для товарного выращивания наибольший интерес представляют молодые рыбы. Обычно в прудах рыбу выращивают 1-2 года. Нормативная и максимальная масса рыб, выращиваемых в прудах к концу сезона (сентябрь-октябрь), представлена в табл. 2.

Таблица 2

Нормативная и максимальная масса рыб, выращиваемых в прудах, к концу сезона (сентябрь - октябрь)

\begin{tabular}{|c|c|c|c|c|c|c|}
\hline \multirow{3}{*}{ Вид рыбы } & \multicolumn{6}{|c|}{ Норма прироста, г } \\
\hline & \multicolumn{2}{|c|}{ 1-buй год } & \multicolumn{2}{|c|}{ 2-ой год } & \multicolumn{2}{|c|}{ 3-ий год } \\
\hline & $\min$ & $\max$ & $\min$ & $\max$ & $\min$ & $\max$ \\
\hline Карп & 25 & 500 & 350 & 1500 & 500 & 1800 \\
\hline Толстолоб & 70 & 300 & 1000 & 1700 & 2000 & 3500 \\
\hline Белый амур & 15 & 25 & 450 & 500 & 900 & 1600 \\
\hline Щука & 40 & 60 & 80 & 120 & 200 & 450 \\
\hline Карась & 25 & 50 & 200 & 300 & 250 & 500 \\
\hline
\end{tabular}

Источник: составлено авторами

При выборе объекта выращивания нужно иметь в виду, что скорость роста рыб далеко не единственный показатель. Учитывать следует также качество воды, кормовую базу и климатическую зону, в которой расположено хозяйство. Интерес представляют некоторые технологии выращивания речной рыбы, и в данной работе они рассмотрены на примере карпа.

Существует несколько технологий выращивания карпа: 1) традиционная; 2) непрерывная.

Наиболее широко применяется первая, включающая двух- или трехлетний цикл выращивания рыбы. Согласно этой технологии, обычно выращивают карпа и растительноядных рыб. При этом используют пруды различных категорий: нерестовые, мальковые, выростные, зимовальные, нагульные. Каждая категория прудов предназначена для выполнения определенного технологического цикла. Возможен вариант, при котором питомные пруды отсутствуют и посадочный материал приобретают в другом хозяйстве. Выращивают рыбу при различном уровне интенсификации. При высоком уровне интенсификации возможно получение рыбопродукции из расчета 5-6 т/га. Эффективность этого способа выращивания требует соблюдения ряда требований: постоянной проточности, технической аэрации воды, регулярного известкования прудов.

В последние годы предложена более простая схема выращивания товарной рыбы - по так называемой непрерывной технологии. Она предусматривает 
подращивание молоди карпа до массы 1-2 г и дальнейшее ее выращивание без пересадок в одном пруду в течение двух лет. При этом требуется только две категории прудов - мальковые и нагульные, где рыба выращивается и зимует.

Одним из приемлемых для владельцев небольших прудов является метод выращивания товарных сеголетков. Эта технологическая схема предусматривает раннее получение личинок, подращивание их на теплой воде до массы 1 г и последующее их выращивание в пруду при разреженной посадке. При хорошей кормовой базе и благоприятном гидрохимическом режиме возможно за один сезон получение товарных сеголетков массой $0,4-0,5$ кг.

Высокоинтенсивный метод рыбоводства - выращивание рыбы в садках и бассейнах. Садки устанавливают в водоемах-охладителях энергетических объектов или естественных водоемах (озерах, водохранилищах). Особенно перспективно выращивание рыбы в садках, установленных в водоемахохладителях. В летний период в садках выращивают теплолюбивых рыб, например карпа, зимой - форель. Использование той или иной технологии связано и с тем, какие виды рыб вы собираетесь выращивать.

В рыбоводческом хозяйстве существует несколько способов и технологий разведения рыбы - экстенсивный способ, полуэкстентивный способ и интенсивный способ.

Экстенсивный способ разведения рыбы используют в прудах с естественной кормовой базой. Полуэкстенсивный способ применяют в садковом разведении, где рыб частично подкармливают. В закрытых установках применяют интенсивный способ выращивания рыб, при котором используют специализированные корма.

Чтобы рыба в пруду или в другом водоеме чувствовала себя хорошо и быстро росла, должна соблюдаться определенная норма запуска рыбы в водоем. От плотности посадки в первую очередь зависит то, сколько продукции удастся получить, если рыба разводится на продажу.

Для питания может использоваться только натуральная пища, но могут и добавляться прикормки - специальные комбикорма. В любом случае, верно выбранные нормы зарыбления на 1 га помогут создать наилучшие условия для разведения [9-13].

Сравнительные результаты относительно затрат на зарыбление водоема площадью 10 га различными способами представлены в табл. 3 и 4.

Таблица 3

Расчёт затрат на зарыбление водоёма площцдью 10 га экстенсивным способом

\begin{tabular}{|l|c|c|c|c|c|}
\hline Вид рыбы & $\begin{array}{c}\text { Количество хво- } \\
\text { стов рыбы, шт. }\end{array}$ & $\begin{array}{c}\text { Масса од- } \\
\text { ной особи, } \mathbf{\Gamma}\end{array}$ & $\begin{array}{c}\text { Масса за- } \\
\text { рыбка, кг }\end{array}$ & $\begin{array}{c}\text { Цена зарыб- } \\
\text { ка, руб/кг }\end{array}$ & $\begin{array}{c}\text { Стоимость } \\
\text { зарыбка, руб. }\end{array}$ \\
\hline Карп & 7600 & $30-35$ & 250 & 96 & 24000 \\
\hline Толстолоб & 1350 & 300 & 400 & 48 & 19200 \\
\hline Белый амур & 1150 & 150 & 175 & 84 & 14700 \\
\hline Щука & 50 & 40 & 2 & 108 & 216 \\
\hline Карась & 4800 & 25 & 120 & 48 & 5760 \\
\hline Всего: & 14950 & - & 947 & - & 62876 \\
\hline
\end{tabular}

Источник: составлено авторами на основе [14] 
Таблица 4

Расчёт затрат на зарыбление водоёма площадью 10 га полуэкстенсивным способом

\begin{tabular}{|l|c|c|c|c|c|}
\hline Вид рыбы & $\begin{array}{c}\text { Количество хво- } \\
\text { стов рыбы, шт. }\end{array}$ & $\begin{array}{c}\text { Масса од- } \\
\text { ной особи, г }\end{array}$ & $\begin{array}{c}\text { Масса } \\
\text { зарыбка, } \\
\text { кг }\end{array}$ & $\begin{array}{c}\text { Цена зарыб- } \\
\text { ка, руб/кг }\end{array}$ & $\begin{array}{c}\text { Стоимость } \\
\text { зарыбка, руб. }\end{array}$ \\
\hline Карп & 45500 & $30-35$ & 1500 & 96 & 144000 \\
\hline Толстолоб & 10000 & 300 & 3000 & 48 & 144000 \\
\hline Белый амур & 8000 & 150 & 1200 & 84 & 100800 \\
\hline Щука & 50 & 40 & 2 & 108 & 216 \\
\hline Карась & 32000 & 25 & 800 & 48 & 38400 \\
\hline Всего: & 95550 & - & 6502 & - & 427416 \\
\hline
\end{tabular}

Источник: составлено авторами на основе [14]

Полученные данные позволяют рассчитать стоимость одного килограмма полученной рыбы, полученной экстенсивным способом (затраты на кормление отсутствуют):

1) 62876 руб. / 6700 кг $=9,38$ руб./кг

2) 6700 кг $* 1000=6700 \mathrm{~T}$

Стоимость одного килограмма полученной рыбы, полученной полуэкстенсивным способом (с учетом затрат на корм 1 кг массы тела рыбы $=3-4$ кг корма; 15000 кг рыбы * 4 кг корма $=60000$ кг корма; 60000 кг * 9,6 руб. = 576000 руб.) составила:

1) 427416 руб. + 576000 руб. = 1003416 руб.

2) 1003416 руб. / 40000 кг = 25,08 руб./кг

В ходе расчета затрат на зарыбление водоёма, площадью 10 га двумя различными методами можно сделать следующие выводы:

- стоимость количества хвостов полуэкстенсивным способом выше, чем экстенсивным;

- масса одной особи одинаковая;

- масса зарыбка полуэкстенсивным способом выше, чем масса зарыбка экстенсивной технологией;

- цена зарыбления за килограмм рыбы одинаковая;

- общая стоимость зарыбления полуэкстенсивным способом составляет 427416 рублей, а стоимость зарыбления экстенсивной технологией составляет 62876 рублей [15].

Таким образом, стоимость зарыбления водоема площадью 10 га полуэкстенсивным способом выше, чем стоимость зарыбления водоема экстенсивным способом.

По медицинским нормам потребность речной рыбы на одного человека в год составляет 14,2 кг. Численность населения ДНР - 1700000 человек. При пересчете на все население Республики годовая потребность в речной рыбе составляет 24140000 кг.

Таким образом, при годовой добыче речной рыбы в размере 40000000 кг с учетом потребностей населения в остатке на экспорт остается 15860000 кг речной рыбы. 
Финансирование развития рыбного хозяйства Республики в условиях нестабильной военно-политической обстановки на данном этапе все еще не велико. Однако, рыбное хозяйство, несмотря на ряд трудностей, развивается, и инвестирование в этой сфере возрастает [16]. Планируемый объем инвестиций разными способами разведения речной рыбы приведен в табл. 5.

Таблица 5

Планируемый объём инвестиций в разведение рыбы различными способами

\begin{tabular}{|l|c|c|}
\hline \multirow{2}{*}{ Общее количество инвестиций, руб. } & \multicolumn{2}{|c|}{ Способы разведения рыбы } \\
\cline { 2 - 3 } & \multicolumn{2}{|c|}{26550000} \\
\hline Сумма государственных инвестиций, руб. & 7965000 & 125400000 \\
\hline Сумма сторонних инвестиций, руб. & 18585000 & 292600000 \\
\hline
\end{tabular}

Источник: составлено авторами на основе [16]

Таким образом, для тех инвесторов, которые захотят вложить свой капитал в экстенсивный способ разведения рыб, их вложения составят 18585000 руб., в то время как при полуэкстенсивном способе - 292600000 руб. Учитывая необходимые объемы вложений в разведение речных рыб, основной проблемой остается привлечение инвестиций в данную отрасль народного хозяйства.

\section{Выводы}

По результатам исследований сделаны следующие выводы.

Разведение рыбы является одним из немногих направлений сельского хозяйства, которое в наименьшей степени подвергается риску неблагоприятных погодных условий. В связи с этим, разведение и реализация рыбы должно заслуживать больше внимания среди современных предпринимателей.

Существует несколько технологий выращивания рыбы (традиционная и непрерывная) и способов разведения рыбы (экстенсивный, полуэкстенсивный, экстенсивный). На что важно обратить внимание предпринимателям ДНР.

Рыбное хозяйство, как вид предпринимательской деятельности, не принесет моментальной прибыли, а даже при наилучших условиях это может быть через 2-5 сезонов (все зависит от скорости роста и ценности породы). Чтобы доход был каждый сезон, при экстенсивном рыбоводстве запускать малька в пруд придется каждый год, пока молодь первого года не станет половозрелой и не начнет самостоятельно размножаться [17].

Для развития рыбного хозяйства внесено предложение по созданию лаборатории для анализа и подтверждения качества рыбной продукции в Новоазовском районе, квоты вылова рыбы, вопросы разработки новых и внесения изменений в существующие нормативные правовые акты в сфере рыбного хозяйства, а также отдельные аспекты взаимодействия рыболовов с контролирующими органами и государственными предприятиями.

\section{Заключение}

Реализация предложений по развитию рыбного хозяйства ДНР позволит решить ряд проблематичных моментов, которые касаются обеспечения 
продовольственной безопасности Республики. К таковым относятся достижение насыщения внутреннего рынка рыбными продуктами, удовлетворение потребностей населения нутриентами рыбного происхождения, снижение розничных цен на рыбную продукцию, расширение рынка труда посредством создания дополнительных рабочих мест. Кроме этого, мероприятия по активизации развития рыбного хозяйства в Республике, позволят повысить доверие потребителей к внутреннему производителю.

Разведение и выращивание водных организмов, особенно ценных в пищевом отношении, приобретает стратегический характер, обеспечивая как возможность организации рационального сбалансированного питания различных возрастных групп населения, так и сохранение экологического равновесия в глобальном масштабе в условиях снижения мирового улова рыбы, в том числе и в нашей Республике.

Потребление рыбной продукции населением в последнее время сократилось. Снижение спроса на рыбную продукцию на отечественном рынке определялось такими факторами, как общее снижение доходов населения; тарифы на доставку рыбной продукции; конкурентоспособность рыбной продукции с заменяющими ее другими продуктами питания; объемы, ассортимент и качество производимой рыбной продукции.

На сегодняшний день наблюдается незначительное увеличение объемов потребления рыбной продукции в ДНР и связано это, в первую очередь, с наиболее рациональным использованием водоемов Республики и снижением стоимости на данную продукцию.

\section{Сиисок источников / References}

1. Нормы потребления рыбы [Normy potrebleniya ryby [Fish consumption rates]]. Available at: http://restorator.name/shkola-pitaniya/ratsionalnoe-pitanie/956-pishchevayatsennost-ryby.html (accessed 14.10.2020)

2. Минимальный набор продуктов питания для основных социальнодемографических групп населения (килограмм/ на одного человека в год) [Minimal'nyy nabor produktov pitaniya dlya osnovnykh sotsial'no-demograficheskikh grupp naseleniya (kilogramm/ na odnogo cheloveka v god) [The minimum set of food products for the main socio-demographic groups of the population (kilogram/per person per year)]]. Available at: https://gisnpa-dnr.ru/wp-content/uploads/2016/10/Sostavpotrebitelskoj-korziny.pdf (accessed 14.10.2020)

3. Рыбное хозяйство Донецкой Народной Республики [Rybnoye khozyaystvo Donetskoy Narodnoy Respubliki [Fisheries of the Donetsk People's Republic]]. Available at: https://gkvrh.ugletele.com/ (accessed 14.10.2020)

4. Состояние водных ресурсов Донецкой Народной Республики [Sostoyaniye vodnykh resursov Donetskoy Narodnoy Respubliki [The state of water resources of the Donetsk People's Republic]]. Available at: https://infourok.ru/sostoyanie-vodnih-resursovgoroda-donecka-problemi-i-perspektivi-1111832.html (accessed 14.10.2020)

5. Зуб В.И., Студенцова Н.А., Бондаренко Л.Г. Перспективы развития сырьевой базы рыбной отрасли на Кубани. Известия ВУЗов. Пищевая технология, 2000, №1, сс. 22-24 [Zub V.I., Studentsova N.A., Bondarenko L.G. Perspektivy razvitiya syr'yevoy bazy rybnoy otrasli na Kubani [Prospects for the development of the raw material base 
of the fish industry in the Kuban]. Izvestiya VUZov. Pishchevaya tekhnologiya = Izvestiya VUZov. Food technology, 2000, no. 1, pp. 22-24.]

6. Филиппова И.Н. Состояние и перспективы развития прудового рыбоводства в Астраханской области. Вестник АГТУ, 2005, №4, cc. 52-59. [Filippova I.N. Sostoyaniye i perspektivy razvitiya prudovogo rybovodstva $\mathrm{v}$ Astrakhanskoy oblasti [State and prospects of development of pond fish farming in the Astrakhan region]. Vestnik $A G T U=$ Bulletin of ASTU, 2005, no. 4, pp. 52-59.]

7. Федоров Е.В. Экономическая эффективность выращивания сеголеток карпа и растительноядных рыб в прудовом хозяйстве Алматинской области Казахстана. Вестник АГТУ. Серия: Рыъбое хозяйство, 2017, №3, сс. 80-88. [Fedorov Ye.V. Ekonomicheskaya effektivnost' vyrashchivaniya segoletok karpa i rastitel'noyadnykh ryb v prudovom khozyaystve Almatinskoy oblasti Kazakhstana [Economic efficiency of growing juvenile carp and herbivorous fish in the pond economy of the Almaty region of Kazakhstan]. Vestnik AGTU. Seriya: Rybnoye khozyaystvo = Bulletin of ASTUю Series: Fisheries, 2017, no. 3, pp. 80-88.]

8. Вопросы развития рыбного хозяйства Донецкой Народной Республики [Voprosy razvitiya rybnogo khozyaystva Donetskoy Narodnoy Respubliki [Fisheries development issues of the Donetsk People's Republic]]. Available at: http://smdnr.ru/tag/rybnoexozyajstvo/ (accessed 14.10.2020)

9. Технологии ведения рыбного хозяйства [Tekhnologii vedeniya rybnogo khozyaystva [Fisheries technologies]]. Available

at: http://barenzevo.arktikfish.com/index.php/akvakultura-barentsevamorya/ekologicheskij/559-3-tekh (accessed 14.10.2020)

10. Правила ведения рыболовного хозяйства и рыболовства [Pravila vedeniya rybolovnogo khozyaystva i rybolovstva [Fisheries and fishing regulations]]. Available at: https://studfiles.net/preview/5440803/ (accessed 14.10.2020)

11. Все о зарыблении водоема: его суть, виды рыб и требования [Vse о zaryblenii vodoyema: yego sut', vidy ryb i trebovaniya [Everything about stocking a reservoir: its essence, types of fish and requirements]]. Available at: https://ferma.expert/ryba/rybovodstvo/razvedenie-rybovodstvo/zaryblenie-vodoemov/ (accessed 14.10.2020)

12. Выращивание сеголетков карпа [Vyrashchivaniye segoletkov karpa [Growing carp underyearlings]]. Available http://ribovodstvo.com/books/item/f00/s00/z0000005/st012.shtml (accessed 14.10.2020)

13. Технология выращивания карпа [Tekhnologiya vyrashchivaniya karpa [Carp growing technology]]. Available https://studbooks.net/833679/agropromyshlennost/tehnologiya_vyraschivaniya_karpa (accessed 14.10.2020)

14. Сущность и направления рыбного хозяйства [Sushchnost' і napravleniya rybnogo khozyaystva [The essence and directions of fisheries]]. Available at: https://studbooks.net/1911045/ekonomika/suschnost_napravleniya_rybnogo_hozyaystv a_sistemy_rybovodstva (accessed 14.10.2020)

15. Нормы зарыбления водоема [Normy zarybleniya vodoyema [Reservoir stocking rates]]. Available at: http://vprud.ru/zarybleniye/normy/ (accessed 14.10.2020)

16. Закон Донецкой Народной Республики о продовольственной безопасности [Zakon Donetskoy Narodnoy Respubliki o prodovol'stvennoy bezopasnosti [Law of the Donetsk People's Republic on Food Security]]. Available at: https://dnrsovet.su/zakonodatelnaya-deyatelnost /prinyatye/zakony/zakon-donetskojnarodnoj-respubliki-o-bezopasnosti-i-kachestve-pishhevyh-produktov/_ (accessed 14.10.2020) 
17. Продовольственная безопасность в области торговли Республики [Prodovol'stvennaya bezopasnost' v oblasti torgovli Respubliki [Food Security in Trade of the Republic]]. Available at: https://mylektsii.ru/11-44495.html (accessed 14.10.2020)

\section{Сведения об авторах / About authors}

Малыгина Валентина Дмитриевна, доктор экономических наук, профессор, заведующий кафедрой товароведения, лаборатория исследований бюджетной политики, Донецкий национальный университет экономики и торговли имени Михаила Туган-Барановского. 283050, Донецкая Народная Республика, г. Донецк, бул. Шевченко, 30, 4 корпус, каб. 4412.

E-mail:mvd-51@mail.ru

Valentina D. Malygina, Doctor of Economic Sciences, Professor, Head of the Department of Commodity Science, Donetsk National University of Economics and Trade named after Mikhail TuganBaranovsky. Of. 4412, Bldg. 4, 30 bul. Shevchenko, Donetsk, Donetsk People's Republic 283050. Email:mvd-51@mail.ru

Антошина Ксения Анатольевна, кандидат экономических наук, доцент кафедры товароведения, Донецкий национальный университет экономики и торговли имени Михаила ТуганБарановского. 283050, Донецкая Народная Республика, г. Донецк, бул. Шевченко, 30, 4 корпус, каб. 4412.E-mail: kseniya.antoshuna@gmail.com

Ksenia A. Antoshina, Candidate of Economic Sciences, Associate Professor of the Department of Commodity Science, Donetsk National University of Economics and Trade named after Mikhail Tugan-Baranovsky. Of. 4412, Bldg. 4, 30 bul. Shevchenko, Donetsk, Donetsk People's Republic 283050.E-mail: kseniya.antoshuna@gmail.com

Гончарова Татьяна Валериановна, кандидат экономических наук, доцент кафедры товароведения, Донецкий национальный университет экономики и торговли имени Михаила ТуганБарановского. 283050, Донецкая Народная Республика, г. Донецк, бул. Шевченко, 30, 4 корпус, каб. 4412.E-mail: goncharowa_tanya@mail.ru

Tatiana V. Goncharova, Candidate of Economic Sciences, Associate Professor of the Department of Commodity Science, Donetsk National University of Economics and Trade named after Mikhail Tugan-Baranovsky. Of. 4412, Bldg. 4, 30 bul. Shevchenko, Donetsk, Donetsk People's Republic 283050.E-mail: goncharowa_tanya@mail.ru 